\title{
Simulasi Otomasi Process Shut Down Deaerator pada Unit Boiler dengan Parameter Suhu dan Level Berbasis PLC Allen - Bradley
}

Muhammad Daffa Pasha

Universitas Indonesia, Depok

\author{
INFORMASI NASKAH \\ Diterima: 9 September 2021 \\ Direvisi: 28 September 2021 \\ Disetujui: 29 September 2021 \\ Terbit: 30 September 2021 \\ Email korespondensi: \\ muhammad.daffa84@ui.ac.id \\ Laman daring: \\ https://doi.org/10.37525/ \\ $\mathrm{sp} / 2021-2 / 295$
}

\begin{abstract}
ABSTRAK
Deaerator merupakan salah satu alat penting pada boiler karena berfungsi sebagai alat untuk mensuplai uap bersih. Tujuan dari observasi adalah membuat sistem shutdown deaerator dengan parameter suhu dan level. Bedasarkan peninjauan langsung dilapangan serta informasi yang diberikan langsung oleh pemimpin unit boiler pada PPSDM Migas cepu pada saat ini sistem Deaerator boiler pada PPSDM Migas Cepu belum mengandalkan penggunaan PLC pada proses safety untuk shutdownnya. Otomasi merupakan suatu teknologi yang digunakan untuk melaksanakan proses industri dengan meminimalkan campur tangan manusia. Teknologi otomasi telah banyak digunakan di dunia industri untuk meningkatkan produktivitas dan mempermudah operator Program PLC (Programmable Logic Control) merupakan salah satu jenis sistem kontrol yang banyak digunakan pada sistem otomasi.

Sistem otomasi pada makalah ini menggunakan PLC Allen Bradley MicroLogic, dengan software RS Logix 5000 dapat mengalihkan proses menjadi terautomasi. Sistem shutdown dibuat untuk mencegah hal buruk yang dapat terjadi pada deaerator seperti meledak karena suhu yang berlebihan. Dari hasil desain program yang dilakukan, Didapatkan simulasi beberapa kondisi antara lain level diatas dan dibawah batas normal serta temperatur diatas dan dibawah batas normal.
\end{abstract}

Kata kunci: Deaerator, Boiler, PLC, SIS 


\section{PENDAHULUAN}

Boiler adalah suatu unit yang digunakan untuk mengubah air sampai menjadi uap bertekanan tertentu. Energi panas dari bahan bakar diberikan kepada air melalui bagian pendidih sehingga terbentuk uap. Untuk menghasilkan uap bertekanan pada boiler diperlukan panas yang berasal dari proses pembakaran bahan bakar yang terjadi diruang bakar. Uap yang dihasilkan oleh boiler dipergunakan untuk menggerakan turbine penggerak listrik, digunakan pada deaerator untuk proses pembersihan air, serta digunakan pada unit wax plant.

Secara sederhana proses pada Boiler dapat digambarkan seperti proses memasak air dimana membutuhkan sumber energi panas. Pemanasan pada Boiler diperoleh dari bahan bakar padat, cair, gas ataupun tenaga listrik. Proses pada boiler dilakukan dengan 3 tahap berikut yaitu Proses pemanasan air sehingga menjadi uap basah, Proses pemanasan uap sehingga menjadi uap jenuh, Dan Proses pemanasan uap jenuh sehingga menjadi uap panas lanjut.

\section{TINJAUAN PUSTAKA}

Fungsi boiler sebagai pengasil uap di PPSDM Migas Cepu digunakan untuk beberapa hal antara lain Proses pengolahan minyak. Penggerak turbine uap, Proses Deaerasi pada Deaerator, Pemanasan minyak berat dan Proses pembersihan pipa dari minyak yang masih tersisa.

Deaerator merupakan alat yang menjadi salah satu bagian dari deaerator yang berfungsi untuk menghilangkan gas terlarut pada air antara lain $\mathrm{O}^{2}$ dan $\mathrm{CO}^{2}$ dengan cara mencampurkan air yang sebelumnya ditampung pada soft water tank dengan uap yang berasal dari accumulator. Suhu normal pengoperasian Deaerator adalah berkisar 70 sampai 90 derajat celcius. Tekanan normal berada pada $0.1 \mathrm{~kg} / \mathrm{cm} 2$, dengan batas tekanan yaitu berada pada $0.05-0.15 \mathrm{~kg} / \mathrm{cm} 2$. Level air normal pada deaerator adalah berada pada kisaran 70-85\%.

Deaerator merupakan komponen paling hilir dari sistem air kondensat. Merupakan pemanas tipe kontak langsung (direct contact heater). Memiliki 2 fungsi utama yaitu untuk memanaskan air kondensat dan sekaligus menghilangkan gas-gas (non condensable gas) dari air kondensat. Media pemanas yang digunakan adalah juga uap ekstraksi. Didalam deaerator terjadi kontak langsung antara air kondesat dengan uap pemanas. Akibat percampuran ini, maka temperatur air kondensat akan naik hingga hampir mencapai titik didihnya. Semakin dekat temperatur air kondensat dengan titik didihnya, semakin mudah pula proses pemisahan air dengan oksigen dan gas-gas lainnya yang terlarut dalam air kondensat. Terdapat 3 proses pada Deaerator yaitu Pemanasan, Agitasi yang merupakan pengadukan yang meliputi spray (penyemprotan) dan tray (tatakan) serta peniupan.

\section{METODE PENELITIAN}

Terdapat beberapa metode yang akan digunakan dalam memperoleh data, menganalisa permasalahan, serta solusi terhadap masalah tersebut. Metode-metode yang digunakan adalah Metode Observasi Lapangan yang dilakukan dengan melihat, mengamati, mencermati dan menganalisa secara langsung ke obyek penelitian dari dekat yaitu berbagai peralatan dan bahan yang digunakan pada lapangan, serta mengetahui karakteristik seperti spesifikasi serta kondisi dari alat dan bahan tersebut ketika melakukan proses observasi. Metode Wawancara dilakukan dengan proses tanya jawab antara peserta dengan narasumber di lapangan, terkait dengan keadaan dan spesifikasi alat serta permasalahan yang akan dibahas pada proses kerja 
praktik, agar memungkinkan untuk memperoleh gambaran nyata mengenai hal-hal yang ada dan terjadi pada lapangan.

Metode Studi Pustaka dilakukan dengan mencari, mengumpulkan, mencermati, dan mencatat berbagai referensi dari sumber-sumber yang ada seperti buku, paper, laporan dan sebagainya yang berkaitan dengan masalah yang akan dibahas pada laporan. Kegiatan pengambilan data beserta observasi lapangan dilaksanakan bertempat di Unit Kilang dan Boiler PPSDM Migas Cepu untuk mencari keperluan data dan spesifikasi alat yang berguna sebagai landasan untuk membuat simulasi PLC. Serta simulasi dengan PLC dilaksanakan bertempat di lab instrumentasi pada PPSDM Migas Cepu dengan aplikasi RS LOGIX 5000. Penelitian ini dilakukan dalam periode waktu dari 2 Juni 2021 s.d. 30 Juni 2021. Penelitian dilakukan pada Unit Boiler PPSDM Migas Cepu

Tabel 1. Spesifikasi Deaerator

\begin{tabular}{|c|c|}
\hline \multicolumn{2}{|c|}{ Deaerator } \\
\hline Manufacturer & Degasing \\
\hline Type & D 2012 \\
\hline Item & V 400L \\
\hline Code & T.E \\
\hline Capacity & $12-18 \mathrm{~m}^{3} / \mathrm{jam}$ \\
\hline Differential Pressure & $0.3 \mathrm{Kg} / \mathrm{Cm}^{2}$ \\
\hline Design Temperature & $150^{\circ} \mathrm{C}$ \\
\hline Total Weight & $1000 \mathrm{Kg}$ \\
\hline
\end{tabular}

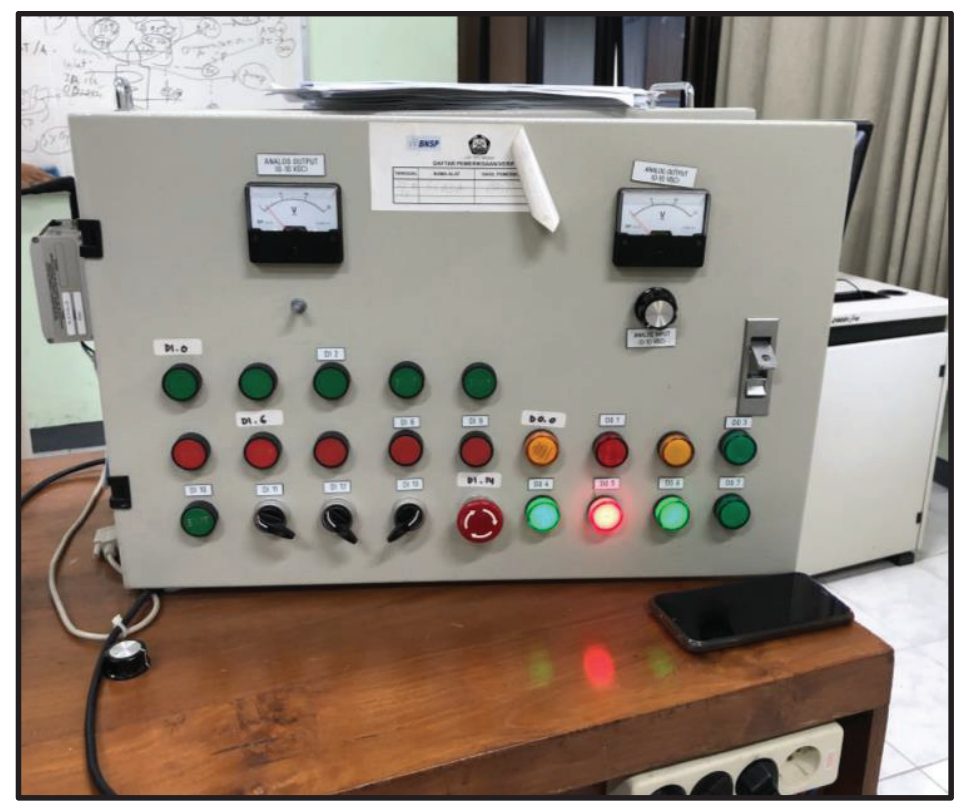

Gambar 1. Unit PLC Allen-Bradley 


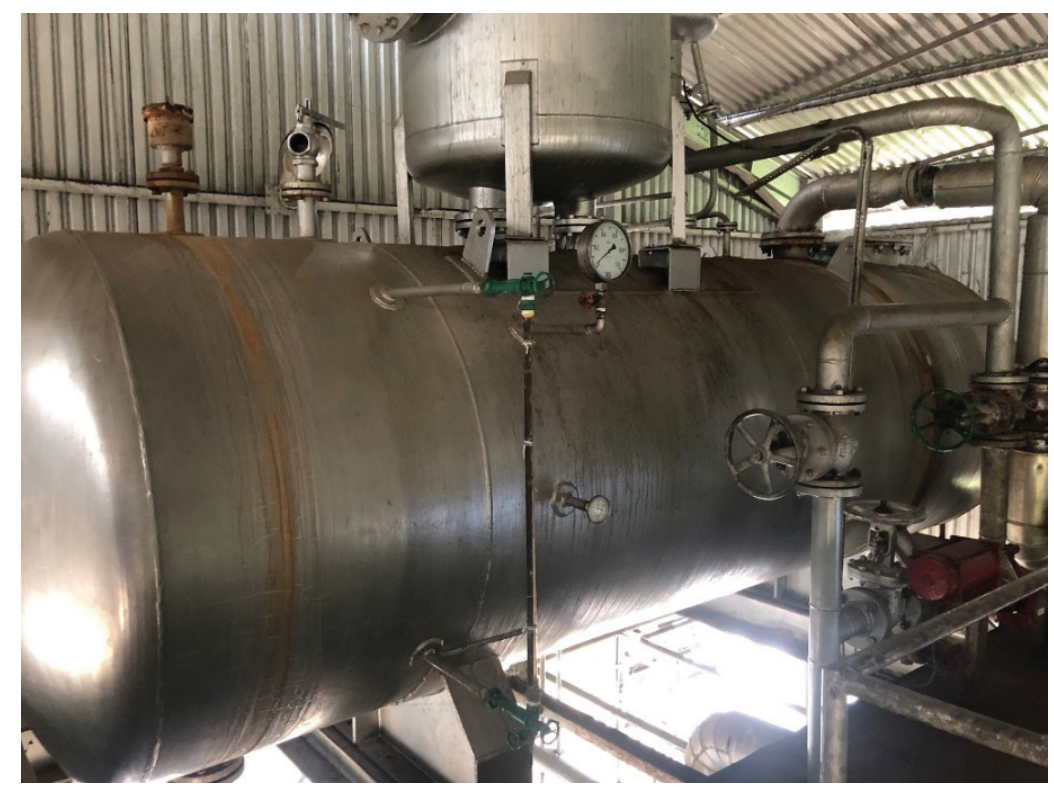

Gambar 2. Deaerator PPSDM Migas CepuMetode penelitian memuat cara pendekatan dan metode penelitian yang digunakan dipaparkan secara tersirat (implisit).

\section{HASIL PENELITIAN DAN PEMBAHASAN}

\section{A. Cara Kerja Sistem}

Bedasarkan Oberservasi dilapangan secara langsung terdapat 4 kondisi yang menandakan bahwa Deaerator berada pada kondisi abnormal antara lain apabila parameter level air berada diatas $85 \%$ dari total persentase ketinggian air pada Deraerator serta berada dibawah keadaan normal yaitu kurang dari $<70 \%$ dari total persentase ketinggian air. Untuk parameter temperature terdapat 2 kondisi abnormal yaitu ketika temperature berada diatas batas normal yaitu melebihi $90^{\circ}$ dan ketika temperature dibawah keadaan normal yaitu dibawah $70^{\circ} \mathrm{C}$.

Pada saat kondisi level air melebihi batas yang ditetapkan, Valve Air akan dinonaktfikan melalui sistem serta proses tetap berjalan sesuai dengan kondisi semula. Tujuan dari menonaktifkan valve air adalah menurunkan level air serta mengoperasikan uap secara normal sehingga proses penguapan tetap berjalan serta menurunkan level air. Pada Saat kondisi level air berada dibawah batas normal yang ditetapkan, maka sistem akan menonaktifkan Valve Uap dan proses pembersihan air menggunakan uap tetap berjalan. Tujuan dari menonaktikan valve uap adalah untuk menyeimbangkan antara supply air dan uap.

Pada saat kondisi temperature melebihi batas yang ditetapkan, maka seluruh sistem deaerator akan dimatikan yang berfungsi untuk mencegah deaerator mengalami kerusakan karenakan suhu melebihi batas yang ditentukan. Pada saat temperatur berada dibawah batas normal maka sistem akan Menonaktfikan Valve Air secara otomatis, kondisi ini disebabkan oleh air yang belebihan sehingga menurunkan temperatur deaerator maka secara otomatis sistem akan menonaktifkan valve air. 
Tabel 2. Truth Table Sistem

\begin{tabular}{|c|c|c|c|c|c|c|c|c|c|c|c|c|}
\hline \multicolumn{2}{|c|}{ INPUT ANALOG } & \multicolumn{3}{|c|}{ INPUT DISKRIT } & \multicolumn{4}{|c|}{ INDIKATOR } & \multicolumn{4}{|c|}{ OUTPUT } \\
\hline Level Transmitter & Temperature Transmitter & Start & Reset & Ack & ㄴH & LL & TH & TL & LCV & TCV & ALARM & SS \\
\hline & & 0 & 0 & 0 & 0 & 0 & 0 & 0 & 0 & 0 & 0 & 0 \\
\hline & & 1 & 0 & 0 & 0 & 0 & 0 & 0 & 1 & 1 & 0 & 0 \\
\hline & $<70^{*} \mathrm{C}$ & 1 & 0 & 0 & 0 & 0 & 0 & 1 & 0 & 1 & 1 & 0 \\
\hline & $<70^{*} \mathrm{C}$ & 1 & 1 & 1 & 0 & 0 & 0 & 0 & 0 & 0 & 0 & 0 \\
\hline & $>90^{*} \mathrm{C}$ & 1 & 0 & 0 & 0 & 0 & 1 & 0 & 0 & 0 & 1 & 1 \\
\hline & $>90^{*} \mathrm{C}$ & 1 & 1 & 1 & 0 & 0 & 0 & 0 & 0 & 0 & 0 & 0 \\
\hline$<70 \%$ & & 1 & 0 & 0 & 0 & 1 & 0 & 0 & 1 & 0 & 1 & 0 \\
\hline$<70 \%$ & & 1 & 1 & 1 & 0 & 0 & 0 & 0 & 0 & 0 & 0 & 0 \\
\hline$>85 \%$ & & 1 & 0 & 0 & 1 & 0 & 0 & 0 & 0 & 1 & 1 & 0 \\
\hline$>85 \%$ & & 1 & 1 & 1 & 0 & 0 & 0 & 0 & 0 & 0 & 0 & 0 \\
\hline
\end{tabular}

\section{B. P\&ID Sistem}

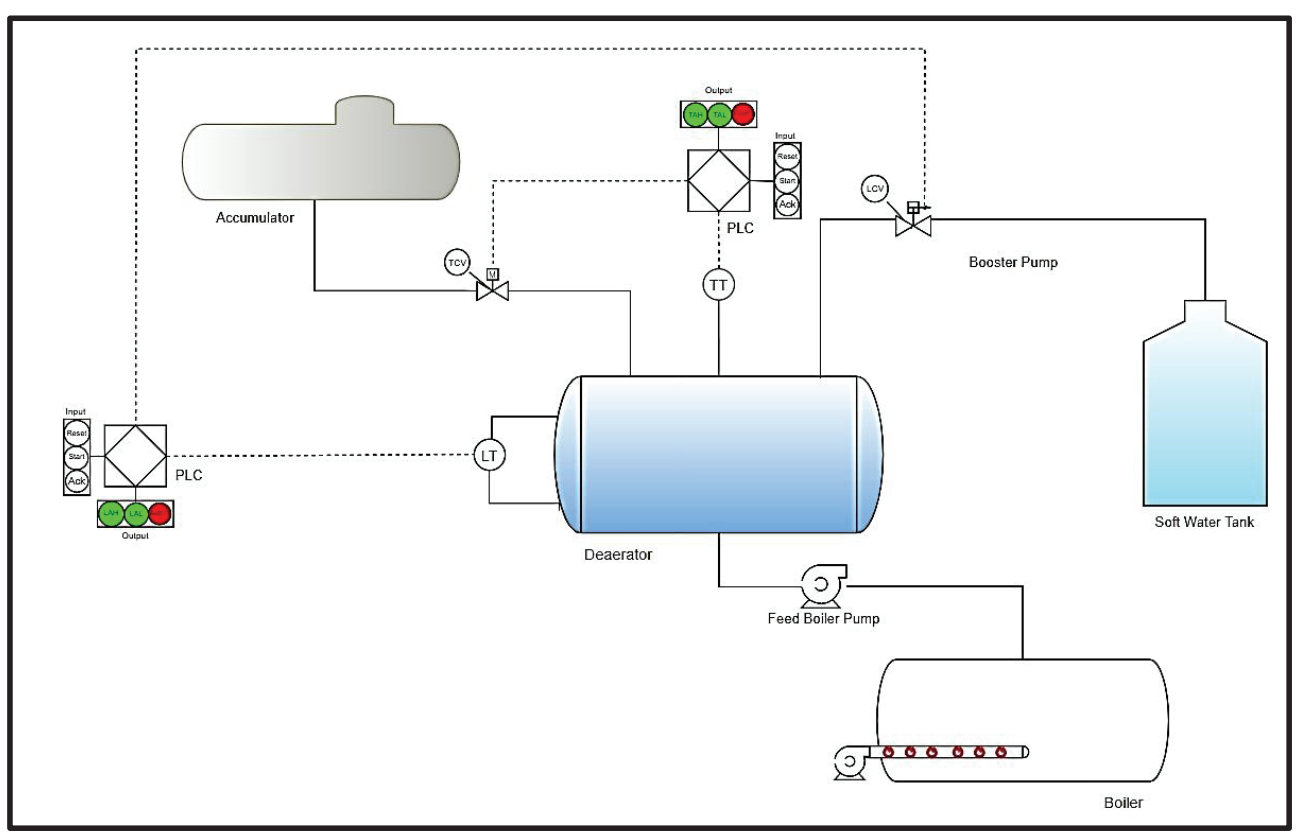

Gambar 3. P\&ID Sistem 


\section{Ladder Diagram dan Simulasi Sistem}
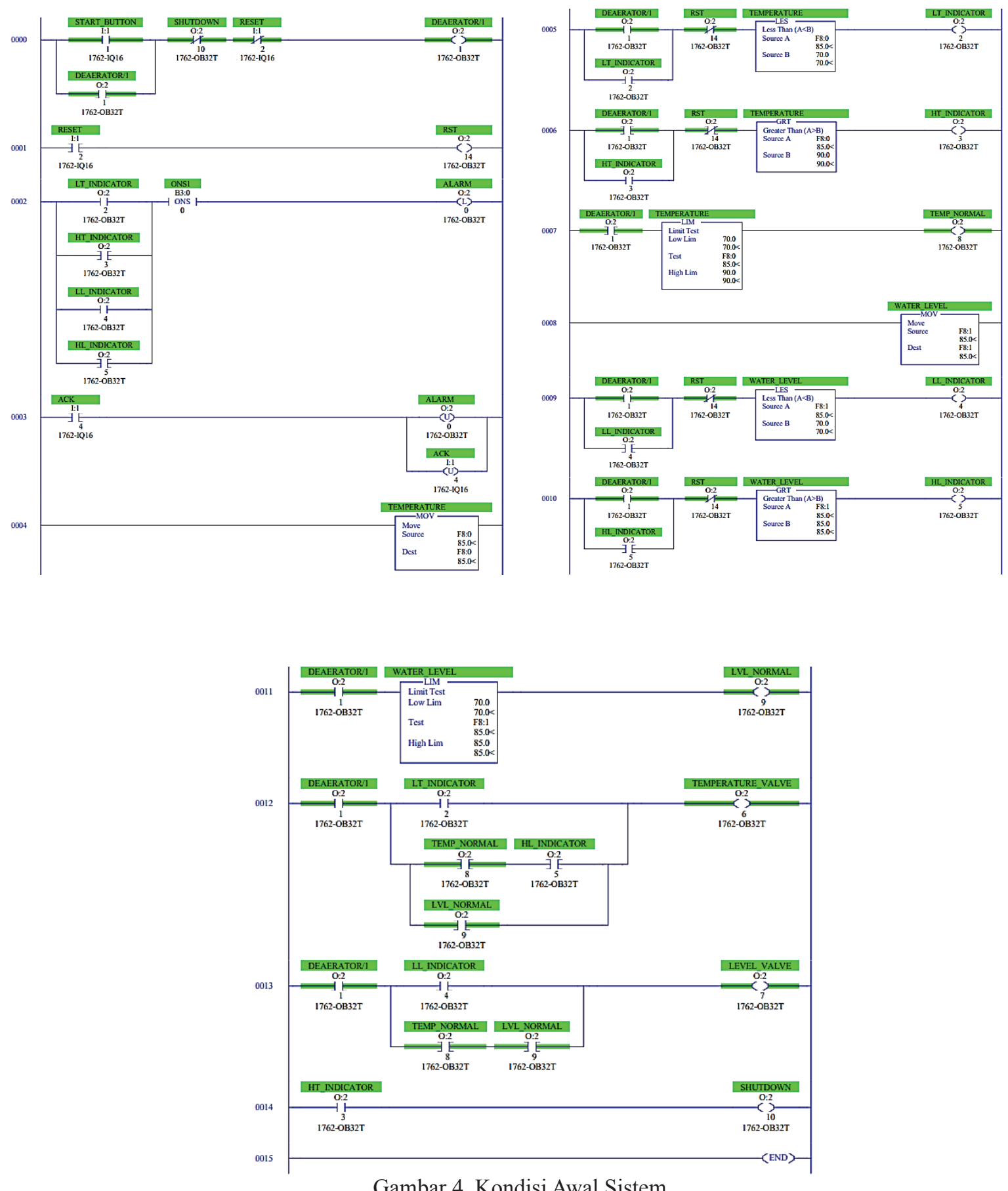

Pada kondisi awal, Sistem deaerator berfungsi secara normal. Seluruh valve beroperasi secara optimal dan semua indikator mati menandakan tidak terdapat kondisi abrnormal pada sistem. Temperatur berkisar $70-90^{\circ} \mathrm{C}$ dan Level air berkisar $70-85 \%$. Pada keadaan ini shutdown valve dinonaktifkan. 

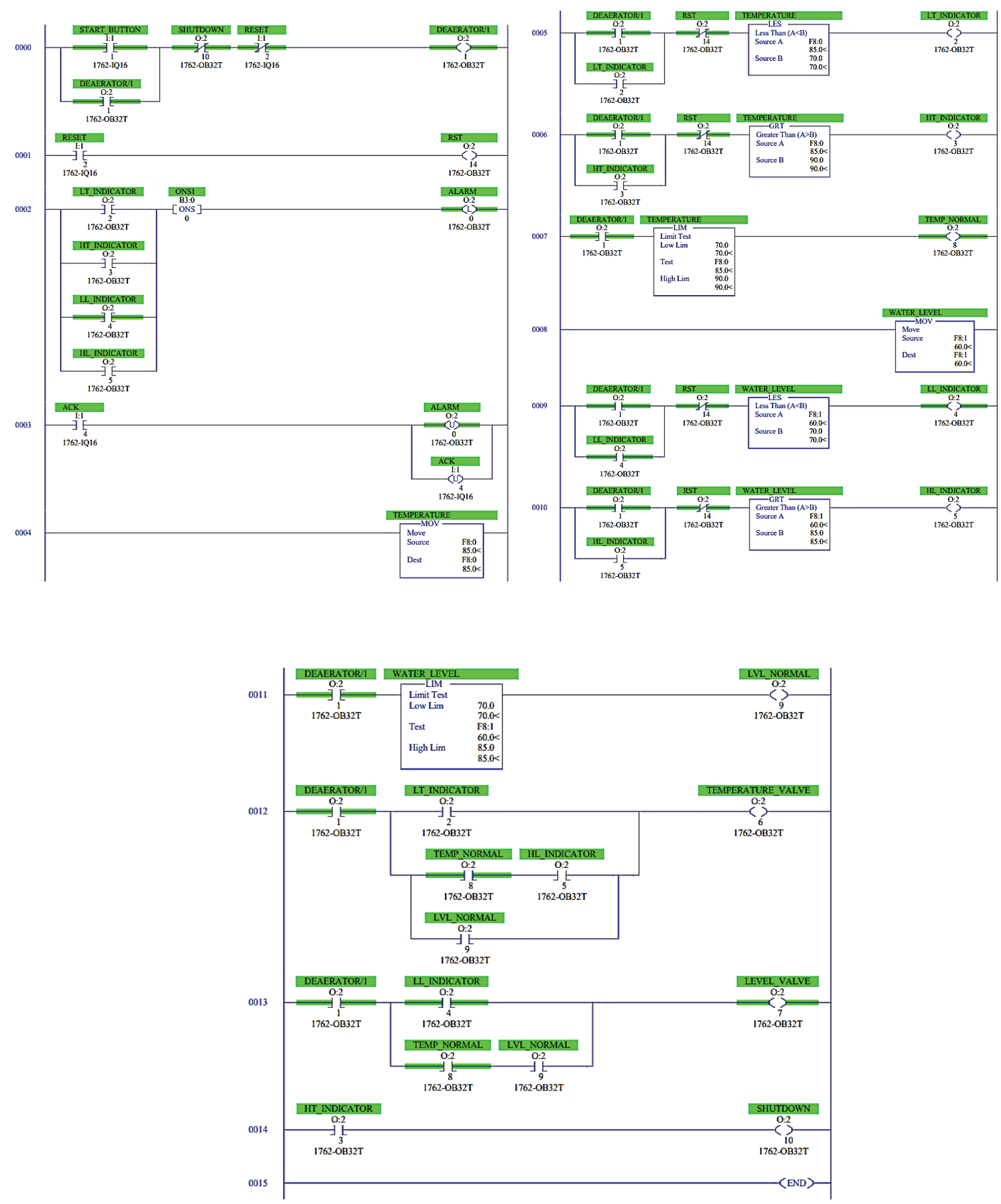

Pada kondisi level dibawah batas 70\%, Sistem deaerator berfungsi secara normal. Temperature control valve akan dinonaktifkan dan Level control valve akan beroperasi dengan tujuan memaksimalkan supply air agar mencapai level air normal. Indikator low level akan menyala menandakan bahwa kondisi ketinggian air berada dibawah batas normal. 

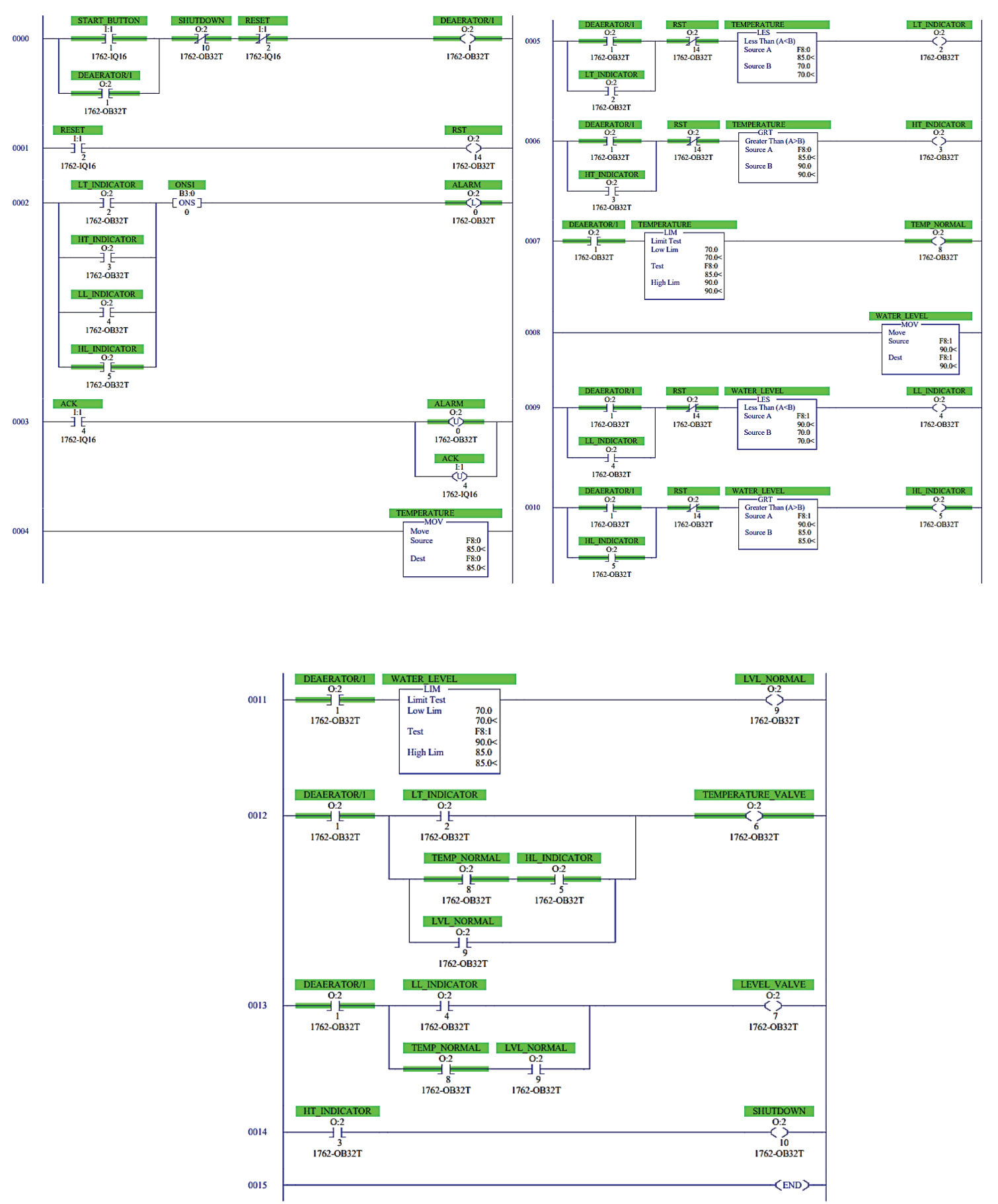

Pada kondisi level melebihi batas normal yaitu 85\%, Sistem deaerator tetap berfungsi secara normal. Level control valve akan dinonaktifkan dan Temperature control valve akan beroperasi dengan tujuan memaksimalkan supply uap agar mencapai kondisi level normal. Indikator high level akan menyala menandakan bahwa kondisi ketinggian air berada diatas batas normal. 

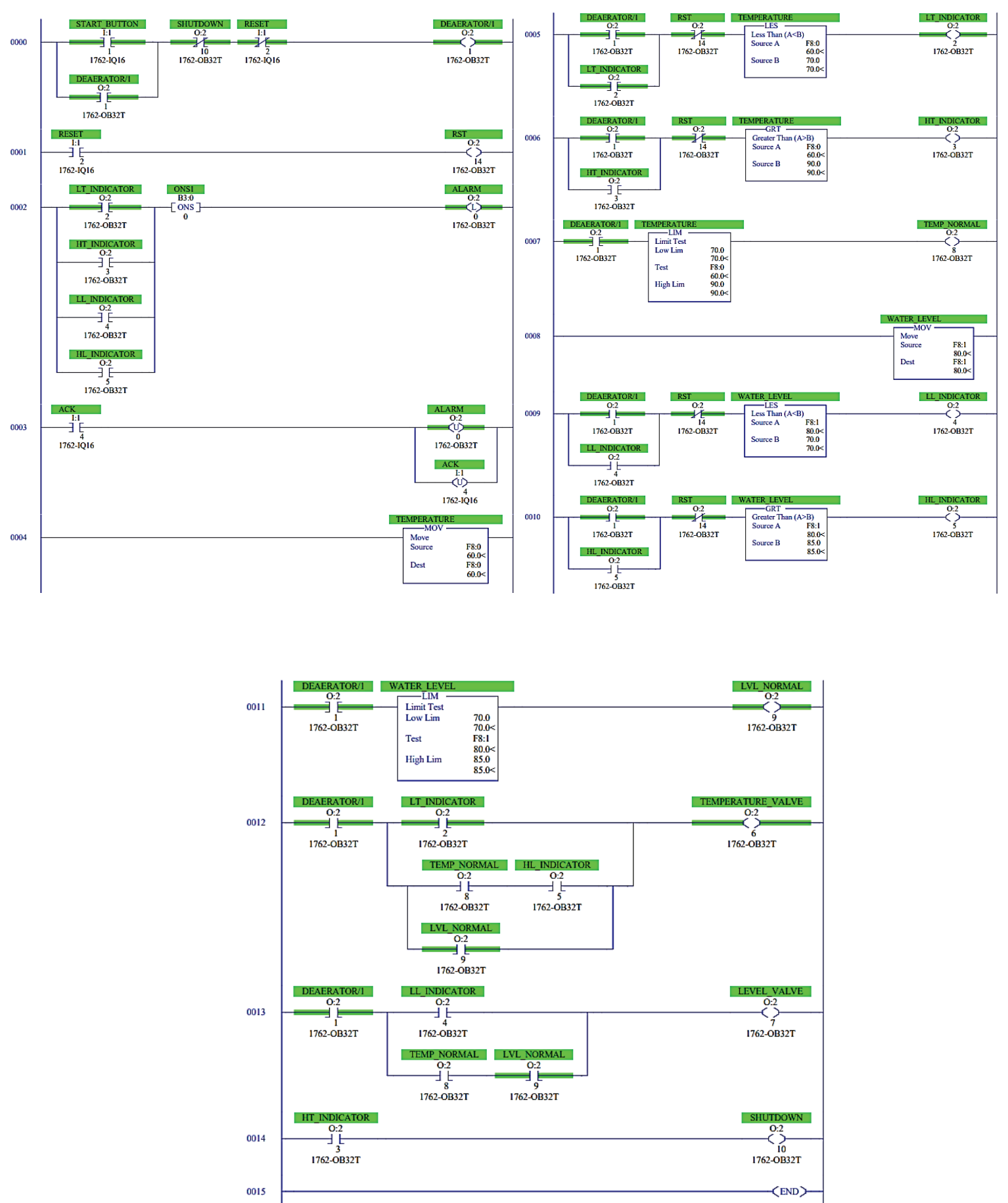

Pada kondisi temperatur berada dibawah batas normal yaitu $70^{\circ} \mathrm{C}$, Sistem deaerator tetap berfungsi secara normal. Level control valve akan dinonaktifkan dan Temperature control valve akan beroperasi dengan tujuan memaksimalkan supply uap agar mencapai temperature normal. Indikator low temperature akan menyala menandakan bahwa kondisi temperature sistem berada dibawah batas normal. 

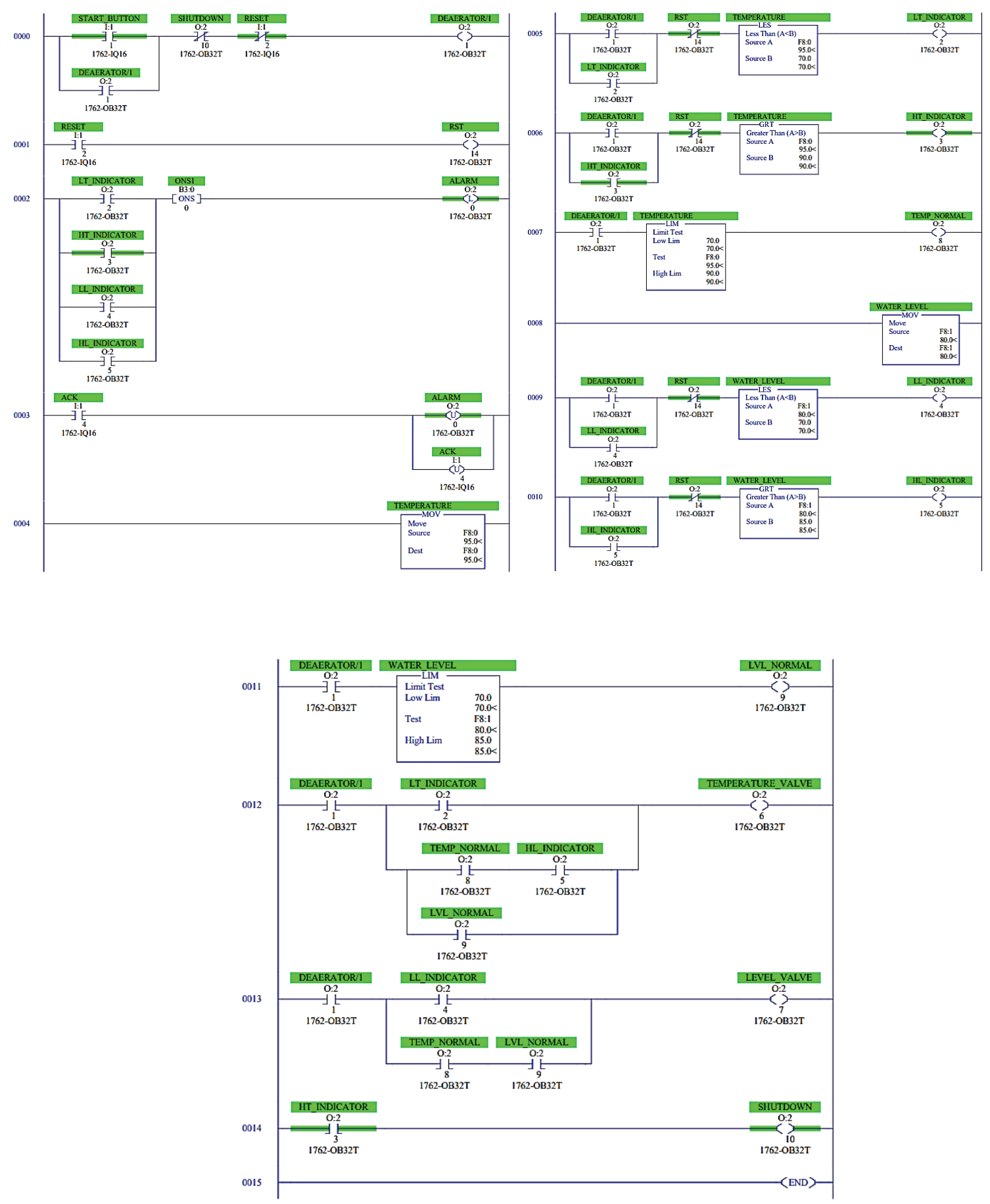

Pada kondisi temperatur diatas batas normal yaitu $90^{\circ} \mathrm{C}$, Sistem deaerator dimatikan. Secara bersamaan seluruh valve akan dimatikan. Indikator shutdown akan menyala menandakan bahwa sistem deaerator seluruhnya mati.

\section{KESIMPULAN}

Setelah melakukan observasi secara langsung di PPSDM Migas secara spesifik pada 
Laboratorium Instrumentasi PPSDM Migas dan melakukan penelitian dengan topik Pengedalian Proses Shutdown Deaerator Pada Unit Boiler dengan parameter Suhu dan Level menggunakan PLC Allen-Bradley, dan akhirnya penulis memperoleh kesimpulan sebagai berikut:

1. Programmable Logic Controller merupakan suatu instrumentasi yang dapat mengendalikan suatu sistem berdasarkan feedback dan diprogram dengan menggunakan ladder logic. Software yang digunakan untuk simulasi program PLC adalah RS LOGIX 500 dengan simulasi yang dilakukan pada perangkat komputer/laptop.

2. Dalam konversi menjadi sistem terotomasi, dibutuhkan peralatan instrumentasi yang controllable seperti control valve dan level transmitter yang sebelumnya valve manual dan sensor level manual.

3. Pengendalian Proses Shutdown Deaerator sangatlah diperlukan guna menjaga Deaerator pada unit boiler dari kondisi yang tidak diinginkan, seperti terjadinya ledakan pada Deaerator dikarenakan temperature berlebih.

4. Besaran utama yang dipakai dalam proses industri Migas adalah temperature, flow, pressure dan level. Dan elemen kendali terdiri dari sensing element, controller dan final element.

5. Pengendalian Proses Shutdown Deaerator dilakukan menggunakan ladder logic pada PLC dengan batas dari parameter temperature dan level air yang sudah ditentukan. Referensi yang diperoleh dilapangan untuk membuat sistem pengedalian proses Shutdown Deaerator didapatkan batas temperature untuk Deraerator beroperasi adalah diantara $70-90{ }^{\circ} \mathrm{C}$ dan Level air Normal Deaerator adalah 70-85\%.

\section{DAFTAR PUSTAKA}

Seborg, D. E., Edgar, T. F., Mellichamp, D. A. \& J.D., Francis (2011). Process Dynamic and Control. John Wiley \& Sons.

Petruzella F. (2017). Programmable Logic Controllers Fifth Edition. McGraw-Hill Education

Bhaskaran, Babu \& Prasath, T \& Sugumar, M \& Thivagarasiva, T. (2016). DESIGN AND FABRICATION OF PRESSING STEAM BOILER. International Journal of Current Trends in Engineering \& Research (IJCTER). 2. 461-473 